\title{
HERMANN HELLER, INTÉRPRETE DE LA CONSTITUCIÓN DE WEIMAR *
}

\section{HERMANN HELLER INTERPRETER OF THE WEIMAR CONSTITUTION}

\author{
Leticia Vita \\ Universidad de Buenos Aires - CONICET (Argentina)
}

SUMARIO: I. INTRODUCCIÓN.- II. ANTIPOSITIVISMO Y PRINCIPIOS JURÍDICOS EN HELLER.- III. LA CONSTITUCIÓN DE WEIMAR: TRES INTERPRETACIONES.3.1. Derechos y deberes fundamentales: una constitución con decisión.- 3.2. Libertad y forma en la Constitución: una constitución para el futuro.- 3.3. Metas y límites de una reforma constitucional: la constitución del Estado social de derecho.- V. CONCLUSIONES

Resumen: A 100 años de la sanción de la Constitución alemana de Weimar, este artículo busca reconstruir la interpretación que hiciera de ella Hermann Heller, uno de los juristas más importantes de la República. Del avanico posible de teorías constitucionales, la de Heller intentó sentar las bases de una interpretación democrática y social de la constitución. Para demostrarlo, analizamos tres textos breves en los que se ocupa específicamente de la constitución de 1919. Partimos del supuesto de que en estos escritos es donde Heller interpreta mejor el programa de la Constitución de Weimar, a la luz de los principios estructurales que la sostienen.

Abstract: 100 years after the enactment of the German Constitution of Weimar, this article seeks to reconstruct the interpretation made by Hermann Heller, one of the most important jurists of the Republic. Of all available constitutional theories, the one of Heller tried to lay the foundations of a democratic and social interpretation of the constitution. To prove this, we will focus on three short articles in which he deals specifically with the constitution of 1919. We assume that in these writings is where Heller best interprets the program of the Weimar Constitution, in light of its structural principles.

Palabras clave: Hermann Heller, Constitución de Weimar, interpretación constitucional, principios jurídicos

Key Words: Hermann Heller, Weimar Constitution, constitutional interpretation, legal principles

Agradezco por su lectura y sus comentarios a Laura Clérico. 


\section{INTRODUCCIÓN}

La Constitución de Weimar ha sido objeto de las más variadas interpretaciones. Sus criticos le han achacado ser el producto de una derrota, una constitución de compromiso, no expresar una decisión clara y, especialmente, haber hecho posible la llegada del horror nazi al poder. Esta última interpretación de la constitución como un texto fallido sigue aún predominando en algunos de sus exégetas, a quienes se les hace dificil deslindar la virtud de sus disposiciones de su suerte final. De esta manera, los aspectos más revolucionarios y novedosos del texto de 1919 suelen quedar en un segundo plano, olvidando que posiblemente la Constitución de Weimar fue una buena constitución, sólo que surgió en un mal momento ${ }^{1}$.

Así, a 100 años de su sanción, cobra interés recuperar la mirada que tuviera sobre ella el jurista socialdemócrata Hermann Heller. Primero, porque su obra intentó sentar las bases de una interpretación democrática y social de la constitución de 1919. De esa manera, podemos rastrear en ella elementos que permiten reconstruir una teoría de la interpretación constitucional orientada al Estado social de derecho. Segundo, porque conocemos bastante sobre el Heller teórico del Estado social de derecho y pionero de una ciencia política democrática en Alemania ${ }^{2}$, pero no nos hemos detenido tanto en su rol como intérprete constitucional.

Cabe recordar, además, que Heller fue un comprometido defensor de la Constitución de Weimar, no sólo desde lo académico. Llegó a arriesgar su vida, junto a su amigo y director Gustav Radbruch, enfrentando a quienes atentaron tempranamente contra la república en el así llamado Putsch de Kapp ${ }^{3}$. Asimismo, actuó como defensor de Prusia en el litigio que tuvo lugar ante el Tribunal Estatal como consecuencia de una intervención inconstitucional del Reich en esa región ${ }^{4}$.

Nuestro objetivo es, entonces, el de reconstruir la interpretación helleriana sobre la Constitución de Weimar. Lo haremos a partir de tres textos breves en los que nuestro autor se ocupa específicamente de ella. Esto no quiere decir que Heller no se refiere a la Constitución de Weimar en otras obras, sino que en ellas

1 Christoph Gusy, 100 Jahre Weimarer Verfassung, Mohr Siebeck, Tübingen, 2018, p. VIII.

2 A modo de ejemplo, algunas de las obras que se han ocupado en extenso de estas cuestiones son: Wolfgang Schluchter, Entscheidung für den sozialen Rechtsstaat: Hermann Heller und die staatscheoretische Diskussion in der Weimarer Republik, Kiepenhever \& Witsch, Koln, 1968; Gerhard Robbers, Hermann Heller: Staat und Kultur, Nomos, Baden-Baden, 1983; Christoph Müller e Ilse Staff (ed.) Der soziale Rechtsstaat. Gedächtnisschrift für Hermann Heller 1891-1933, Nomos, Baden-Baden, 1984; Christoph Müller e Ilse Staff (ed.) Staatslehre in der Weimarer Republik. Hermann Heller zu ehren, Suhrkamp, Frankfurt am Main, 1985; Michael Henkel, Hermann Hellers Theorie der Politik und des Staates, Mohr Siebeck, Tübingen, 2011 y Sebastián Martín, "Los fundamentos sociales, politicos y jurídicos del "soziale Rechtsstaat". Una relectura de Hermann Heller (1891-1933)", Res publica: revista de filosofia politica, n. 25, 2011, pp. 151-176.

3 Ver Hans Schneider, "Positivismus, Nation und Souverenänität. Über die Beziehungen zwischen Heller und Radbruch", en Christoph Müller e Ilse Staff (eds.), Staatslehre in der Weimarer Republik. Hermann Heller zu ehren, op. cit., pp. 176-193.

4 Sobre el caso y la intervención de Heller en el proceso me ocupé en Leticia Vita (ed.) Prusia contra Reich ante el Tribunal Estatal. La sentencia que enfrentó a Hermann Heller, Carl Schmitt y Hans Kelsen en Weimar, Universidad Externado de Colombia, Bogotá, 2015. 
la constitución de 1919 no es su principal objeto de estudio ${ }^{5}$. Nos ocuparemos de: "Derechos y deberes fundamentales" (Grundrechte und Grundplichten) que publica en el año 19246, "Libertad y forma en la Constitución del Imperio"7 (Freiheit und Form in der Reichsverfassung) un discurso que diera con motivo del aniversario de la constitución celebrado por la asociación alemana de estudiantes en 1930 y finalmente, "Metas y limites de una reforma de la Constitución alemana" (Ziele und Grenzen einer deutschen Verfassungsreform) ${ }^{8}$, publicado por primera vez en el año 1931. Partimos del supuesto de que en estos escritos es donde Heller interpreta mejor el programa de la Constitución de Weimar, a la luz de los principios estructurales que la sostienen.

Por último, cabe destacar que estos textos, no tan difundidos en el mundo de habla hispana como otros del mismo autor, se ocupan principalmente de las disposiciones de la segunda parte de la constitución. Este aspecto cobra especial importancia en tanto la interpretación de esa sección constituyó un área novedosa para la disciplina del derecho público de la época9 ${ }^{9}$. Por primera vez los juristas se encontraban con el desafio de interpretar derechos sociales y otras disposiciones de contenido social con rango constitucional.

\section{ANTIPOSITIVISMO Y PRINCIPIOS JURÍDICOS EN HELLER}

Los juristas de Weimar teorizaron desde la crisis sobre una disciplina que, entendian, se encontraba en crisis. No sólo desde el punto de vista metodológico sino también teórico ${ }^{10}$. Esta circunstancia llevó a que la teoría jurídica se planteara una sustancial discusión sobre sus métodos y sus objetivos que se conoce como "Methodenstreit". Esta polémica no consistió simplemente en una

\footnotetext{
5 Existen algunos otros escritos breves en los que se ocupa de algún aspecto puntual de la Constitución de Weimar pero que no se dirigen en particular a las disposiciones sociales. Me refiero a "Die Gleichheit in der Verhältniswahl nach der Weimarer Verfassung" (1929); "Das Berufsbeamtentum in der deutschen Demokratie" (1930); "Die Neuordnung des Reiches im Verhältnis zu seinen Ländern” (1931) y a "Ist das Reich verfassungsmässig vorgegangen?” (1932). Todos ellos incluidos en el segundo tomo de sus obras completas.
}

6 Hermann Heller, "El derecho constitucional de la República de Weimar. Derechos y deberes fundamentales. Sección V: De la Economia”, en Hermann Heller, Escritos Politicos, Alianza, Madrid, 1985, pp. 269-282, publicado en alemán como "Grundrechte und Grundplichten", en Hermann Heller, Gesammelte Schriften. II Recht, Staat, Macht, J. C. B. Mohr, Tübingen, 1992, pp. 281-318.

7 Herman Heller, "Libertad y forma en la Constitución del Imperio", en Hermann Heller, El sentido de la politica y otros ensayos, Pre-textos, Valencia, 1996. Título original: "Freiheit und Form in der Reichsverfassung”, publicado por primera vez en Die Justiz. Monatsschrift für Erneuerung des deutschen Rechtswesens, zugleich Organ des Republikanischen Richterbundes, Verlag Walther Rothschild, Berlin, 5, 1929/30, pp. 672-677.

8 Hermann Heller, "Metas y límites de una reforma de la Constitución alemana", en Hermann Heller, El sentido de la politica y otros ensayos, op. cit., pp. 69-74 en alemán "Ziele und Grenzen einer deutschen Verfassungsreform", publicado por primera vez en Neue Blätter für den Sozialismus. Zeitschrift für geistige und politische Gestaltung (ed. Por E. Heimann y otros), Alfred Protte Verlag, Postdam, 2, 1931, pp. 576-580.

9 Michael Stolleis, Geschichte des öffentlichen Rechts in Deutschland. Weimarer Republik und Nationalsozialismus, Beck, München, 2002, p. 109.

10 Arthur Jacobson y Bernhard Schlink (edit.) Weimar: a jurisprudence of crisis, University of California Press, Berkeley, 2000, p.1. 
disputa académica, sino que en el fondo, era una discusión general acerca del lugar que ocupaba la disciplina en una década convulsionada ${ }^{11}$. Sus participantes eran conscientes de que lo que se debatía en realidad era la posibilidad de la existencia de la república, porque lo que se jugaba detrás era la viabilidad de un derecho democrático en el contexto de la herencia imperial.

La pregunta central que orientó esta discusión era la de la unidad del derecho y del Estado, y los métodos que había que utilizar para delimitarla ¿Debía el derecho ser definido sobre la base de puros conceptos jurídicos o había que considerar elementos sociales, políticos o históricos? La respuesta dividió a los participantes de la polémica en dos grupos: positivistas y no positivistas. En esa discusión lo que predominaba era la acusación a la "escuela de Laband" de haber vaciado el contenido de la teoría del derecho. En esta línea, Kelsen era identificado como el ejecutor final de la tradición positivista, y por lo tanto, era visto como el principal contrincante.

La Teoría Pura del derecho (Reine Rechtslehre) de Kelsen, no sería publicada hasta 1934, sin embargo, su Problemas Capitales de la Teoría Jurídica del Estado (Hauptprobleme der Staatsrechtslehre) de 1911, y la Teoría General del Estado (Allgemeine Staatslehre) de 1925, habian sido suficientes para desencadenar enérgicas reacciones por parte de los más importantes juristas de la época. Tanto la Crítica a la filosofia del derecho neokantiana (Kritik der neukantischen Rechtsphilosophie) de Erich Kaufmann, la Teoría de la Constitución (Verfassungslehre) de Schmitt, la Constitución y Derecho Constitucional (Verfassung und Verfassungsrecht) de Smend y la póstuma Teoría del Estado (Staatslehre) de Heller, pueden leerse en esos términos.

El antipositivismo nucleaba muy distintas posiciones politicas, pero tal vez la única postura realmente comprometida con los valores democráticos era la de Heller $^{12}$. En efecto, Heller formaba parte del grupo de juristas socialistas que, pese a sus diferencias teóricas, políticas y personales, coincidian en defender a la democracia como forma política y al Estado como herramienta de la lucha de clase $^{13}$. Nuestro autor era por lo tanto, un socialdemócrata reformista, tributario también de la concepción constitucional de Ferdinand Lassalle ${ }^{14}$. Sin embargo, al momento de su adhesión al partido, hizo constar su desacuerdo con el materialismo histórico e internacionalismo obrero.

En su concepción sobre el derecho tienen un papel fundamental lo que Heller llama "Rechtsgrundsätzen", los principios jurídicos fundamentales ${ }^{15}$. Éstos

11 Sobre el tema ver especialmente Michael Stolleis, Der Methodenstreit der Weimarer Staatsrechtslehre - ein abgeschlossenes Kapitel der Wissenschaftsgeschichte?, Steiner, Stuttgart, 2001.

12 Ver Kathrin Groh, Demokratische Staatsrechtslehrer in der Weimarer Republik, Mohr Siebeck, Tübingen, 2010.

13 Carlos Miguel Herrera, Derecho y socialismo en el pensamiento jurídico, Universidad Externado de Colombia, Bogotá, 2002, p. 137.

14 Expresada en Ferdinand Lassalle, Über Verfassungswesen. Rede am 16. April 1862, Europäische Verlagsanstalt, Hamburg, 1993. En español en Ferdinand Lassalle, ¿Qué es una Constitución?, Cenit, Madrid, 1931.

15 Sobre esta idea en Heller me he ocupado en Leticia Vita, "La noción de principios jurídicos en la teoria del derecho de Hermann Heller", Isonomía. Revista de teoría y filosofía del derecho, $\mathrm{N}^{\circ} 43$, 2015, pp. 49-75. 
tienen importancia para la existencia y la interpretación de la constitución y se caracterizan porque, como carecen de una concreción suficiente, no pueden encontrar aplicación como normas inmediatas para la decisión judicial. Sin embargo, advierte Heller "son imprescindibles en la constitución jurídica del Estado como normas sociales de ordenación, así como también en cuanto reglas interpretativas para la decisión judicial"16. Para el autor, la validez de esos principios es de naturaleza general y en parte aprioristica, pero lo importante, que lo diferencia de una visión iusnaturalista, es que tienen una naturaleza que es históricamente variable, dependen de cada cultura y deben ser positivizados por la acción del poder legislativo y la interpretación constitucional.

Heller concluye que sin apelar a estos principios, aun en los casos en que el legislador no se remite expresamente a ellos, no se pueden comprender, ni interpretar, ni aplicar la mayoría de los preceptos positivos del derecho constitucional. Así, lo esencial de su punto de vista sobre el derecho es que no puede ser abarcado en su totalidad en la letra de los preceptos jurídicos positivos, sino que la mayoría de los preceptos jurídicos y, sobre todo los más importantes, cobran únicamente sentido cuando se ponen en relación con los principios que son expresión de la estructura social.

En resumen, su concepción del derecho puede ser interpretada como una "sintesis" entre el normativismo kelseniano y el decisionismo de Schmitt17. E1 derecho es para Heller derecho positivo pero también se inspira en principios suprapositivos, que emanan de una comunidad concreta. En su visión es tan importante el momento de la normatividad como el de la decisión que positiviza estos principios. Se podría concluir que su concepto de derecho mantiene la tensión entre derecho positivo y principios, por lo que supera una definición positivista del derecho pero se aleja al mismo tiempo de una comprensión decisionista del mismo.

\section{LA CONSTITUCIÓN DE WEIMAR: TRES INTERPRETACIONES}

Como sostuvimos en la introducción, para reconstruir la interpretación que hace Heller de la Constitución de Weimar nos concentraremos en tres textos breves en los que se refiere explicitamente a ella. Resta destacar el contexto, muy diferente, en el que cada uno de estos artículos fue escrito. El de 1924 se corresponde a los primeros años de la república, y en particular, a una de las etapas de mayor tanquilidad en medio de la crisis. En efecto, de 1924 a 1928 fue la primera vez que el Reichstag agotó un período parlamentario completo. Los otros dos escritos son de principios de los años treinta, cuando la constitución comenzó a enfrentar los más definitivos ataques. Recordemos que desde 1929 la crisis económica coincidió con la inauguración del período conocido como Präsidialregierung, durante el cual el parlamento nunca más logró formar una mayoría y el Presidente del Reich gobernó por medio de los decretos habilitados por el artículo 48 de la constitución. 275 .

16 Hermann Heller, Teoría del Estado, Fondo de Cultura Económica, Buenos Aires, 1992, p.

${ }^{17}$ Sobre este punto ver David Dyzenhaus, Legality and Legitimacy: Carl Schmitt, Hans Kelsen and Hermann Heller in Weimar, Oxford University Press, Oxford, 1999. 


\subsection{Derechos y deberes fundamentales: una constitución con decisión}

En "Derechos y deberes fundamentales", Heller lleva a cabo un detallado análisis de la Constitución de Weimar en lo que refiere a la sección de derechos y deberes. Sin embargo, si bien es cierto que se ocupa allí tanto de los derechos liberales como de los sociales, es en su interpretación sobre los artículos de la sección V de la constitución (artículo 151 al 165), donde encontramos las ideas más sugerentes. De alguna manera, en ese análisis parece responder a la acusación de algunos de sus contemporáneos, que como Carl Schmitt, veían a la constitución de 1919 como un texto sin decisión, resultado del compromiso entre las ideas liberales y las socialistas.

Recordemos que años más tarde, Carl Schmitt publicaría en su Teoría de la Constitución que el texto de 1919, si bien contenía las "decisiones políticas fundamentales" expresaba "compromisos y oscuridades" sin decisión alguna y en los que, por el contrario, los "partidos de coalición buscaron soslayar una decisión"18. De esta manera, para Schmitt la constitución aplazaba el verdadero combate politico, a partir de una formula conciliatoria que organizaba elementos para él irreconciliables ${ }^{19}$.

Heller, en cambio, interpreta en este texto de 1924 que la mixtura de elementos liberales y sociales de la Constitución de Weimar refleja las relaciones de fuerzas existentes al momento de sancionarla. Ve en ella una decisión por un modelo conciliador, un "acuerdo recíproco orientado al fin de una más justa distribución de los recursos" 20 . En clara sintonía con la definición lassallana de constitución, sostiene que para que una constitución no quede en el papel, debe ofrecer instrumentos legales a través de los cuales las relaciones existentes puedan "ser traducidas en relaciones jurídicas que respondan a las ideas dominantes de la Moral y de la Justicia"21.

Por eso interpreta que la Constitución de Weimar no garantiza su continuación sino que promete "su transformación legal a tenor de las líneas programáticas", previendo las leyes-marco (Rahmengesetz) que servirán de fundamento "a la transición de la propiedad privada a una propiedad comunitaria"22. De esta manera, vemos que Heller coincide con la posición oficial del Partido Socialdemócrata Alemán, al entender a las nuevas disposiciones sociales como programáticas. Por contraste a la "existencia material" de las ideas del liberalismo y la democracia, las ideas socialistas, concluye, han permanecido hasta ahora "esencialmente en ideologia" y se las ha entendido como "sin fuerza jurídica de obligar", sin una "praxis cierta", que pueda "plasmarse en un Derecho cierto"23.

18 Carl Schmitt, Teoría de la Constitución, Alianza, Madrid, 2006, p. 52.

19 Como es sabido, esta tesis fue continuada, entre otros, por Otto Kirchheimer. Ver Otto Kirchheimer, Weimar und was dann? Entstehung und Gegenwart der Weimarer Verfassung, Laub, Berlín, 1930.

${ }^{20}$ Hermann Heller, "El derecho constitucional de la República de Weimar. Derechos y deberes fundamentales. Sección V: De la Economía", op. cit., p. 271.

${ }_{21}^{1}$ Ídem.
${ }_{22}$ Ídem.
23 Ídem. 
En efecto, el partido interpretaba a los nuevos preceptos como "bases programáticas" (programmatische Grundlage) que no podian ser invocadas en sede judicial sin una ley reglamentaria del Parlamento. Recordemos que la socialdemocracia buscaba restringir el papel de la justicia de Weimar antidemocrática y conservadora- a la hora de interpretar estos nuevos derechos $^{24}$. Su apuesta, que es la misma de Heller, era al poder legislativo, en el que tenían garantizada una mayoría. No al poder judicial dispuesto a frenar todo tipo de legislación social. En este contexto cobran relevancia las palabras de Otto Kahn-Freund: en Weimar, ser democrático era ser positivista ${ }^{25}$.

Heller destaca además que los constituyentes de 1919 le dieron una gran importancia a la sección "De la Economía”, algo que distinguía a la Constitución de Weimar de las demás, ya que "no era dado encontrar en ninguna constitución precedente"26. En estas disposiciones se hallan para él muchas ideas "propiamente socialistas", que se definen por encontrar en la propiedad privada "la raíz del mal y aspirar, por consiguiente, a su socialización" 27. Es interesante notar que Heller habla del despliegue de "las ideas sociales, por algún tiempo aún no las ideas socialistas" 28 . Como veremos más adelante, interpreta a la constitución como un texto dinámico.

Asimismo, Heller entiende que estas disposiciones engloban la tensión entre una concepción económica individualista (capitalista) de la burguesía y su reforma socialista. En efecto, al comentar los artículos 151 a $154^{29}$ destaca que esa sección evidencia "la huella" que deja la dificultad de conciliar el desequilibrio de los antagonismos sociales. Mientras el artículo 151, establece que la organización de la vida económica debe responder a los principios de

\footnotetext{
24 Sobre la justicia en Weimar ver entre otros Ernst Fraenkel, Zur Soziologie der Klassenjustiz und Aufsätze zur Verfassungskrise 1931-32, Wissenschaftliche Buchgesellschaft, Darmstadt, 1968 y Anthony Mcelligott, "Dangerous communities and conservative authority: the judiciary, Nazis and rough people, 1932-1933", en Tim Kirk y Anthony Mcelligott (edit.), Opposing Fascism. Community, Authority and Resistance in Europe, Cambridge University Press, Cambridge, 2004, pp. 33-47.
}

25 Ewan McGaughey y Otto Kahn-Freund, "Autobiographical Memories of the Weimar Republic: A Conversation with Wolfgang Luthardt (February 1978)", disponible en: https://ssrn.com/abstract=2768439, 2016.

26 Hermann Heller, "El derecho constitucional de la República de Weimar. Derechos y deberes fundamentales. Sección V: De la Economia”, op. cit., pp. 270-271.

27 Ídem.

28 Ibid., pp. 272-273.

${ }^{29}$ Recordemos que el 151 establecía que la organización de la vida económica debía responder a los principios de justicia, con la aspiración "de garantizar a todos la procura de una existencia digna" pero agregaba al mismo tiempo que dentro de esos límites se debía "proteger la libertad económica de los individuos", a la par que garantizaba "la libertad de comercio e industria dentro de los limites establecidos por las leyes del Reich". Por su parte, el artículo 152 garantizaba la libertad de contratación al mismo tiempo que prohibía la usura y garantizaba la nulidad de los actos jurídicos "contrarios a las buenas costumbres" y el artículo 153 garantizaba el derecho de propiedad aclarando que la expropiación sólo podría realizarse cuando lo requiriera el interés público y existiera una base legal para ello e indemnización posterior. Agregaba también que la propiedad imponía "obligaciones" y que su uso "debe constituir al mismo tiempo un servicio para el bien común". Por último, el artículo 154 se dedicaba al derecho sucesorio, estableciendo que el mismo se regulaba por el derecho civil y que una ley determinaría la parte de la herencia que corresponde al Estado". 
"justicia", con la aspiración "de garantizar a todos la procura de una existencia digna" 30 anunciando "la realización del principio ético fundamental del socialismo (ethischen Grundgedankens des Sozialismus)"31, el resto de los apartados y los artículos 153 y 154 afianzan los pilares básicos de la economía individualista: libertad económica del individuo, libertad de comercio y de industria, libertad de contratación, propiedad privada y derecho a la herencia.

Otro ejemplo de este tipo de disposiciones sería la forma de regular el derecho de propiedad que tiene la constitución. Inmediatamente después de garantizar la propiedad privada, se proclama que ésta puede ser expropiada en cualquier momento-eventualmente sin indemnización- por ley del Reich. Entonces, ya no se trata de un derecho fundamental o por principio "inviolable" o "sagrado", como proponía la concepción liberal, sino que "impone obligaciones y debe atender simultáneamente, junto a la satisfacción de las necesidades individuales, a una función social" 32 . De la misma manera, al lado de la garantía constitucional de la herencia, se incluye el impuesto estatal a la misma.

En cambio, los artículos 155, sobre el reparto y aprovechamiento del suelo ${ }^{33}$ y el 156, sobre socialización ${ }^{34}$, son interpretados por el jurista socialdemócrata como dos disposiciones de auténtico contenido socialista que regulan la relación de la comunidad estatal de la tierra y las empresas e indican "las vías prácticas que conducen a la economía comunitaria"35. El 155 contiene, en efecto, los principios de "reforma del suelo por los que se habrá de guiar el futuro legislador"36.

Por último, de especial interés es el comentario que hace Heller del artículo 165 de la Constitución, aquel que diseña la creación de consejos de trabajadores y de empresas ${ }^{37}$. Recordemos que este artículo no se encontraba originalmente en

30 Precursor de la idea de derecho a la existencia digna o mínimo existencial concretizado a partir de la interpretación de la Grundgesetz de 1949 en especial en relación con el artículo 1 (dignidad), artículo 3 (igualdad) y artículo 20 (Estado Social de Derecho).

${ }^{31}$ Hermann Heller, "El derecho constitucional de la República de Weimar. Derechos y deberes fundamentales. Sección V: De la Economia", op. cit., p. 272.

32 Ídem.

33 Establecía que el reparto y el aprovechamiento del suelo "será inspeccionado de manera que impida los abusos, y tienda a la meta de que cada alemán cuente con una vivienda digna, y que todas las familias alemanas, especialmente las numerosas, tengan a su disposición un hogar y un patrimonio económico adecuado a sus necesidades domésticas". Además establecía que la propiedad podría ser expropiada "para las necesidades de vivienda, el fomento de la colonización o roturación y la mejora de la agricultura" y que el cultivo y la explotación de la tierra era un deber del propietario para con la colectividad.

${ }^{34}$ Este artículo sostenía que el Reich podía socializar "aquellas empresas económicas privadas apropiadas" y también agrupar "a los fines de la explotación colectiva" a empresas y sociedades económicas, con el objetivo de "asegurar la colaboración de todos los elementos productores, dar participación en la administración a patronos y obreros, y regular, de acuerdo con los principios de la economía colectiva, la extracción, elaboración, reparto, inversión, y fijación de precios, así como la importación y exportación de productos".

${ }^{35}$ Hermann Heller, "E1 derecho constitucional de la República de Weimar. Derechos y deberes fundamentales. Sección V: De la Economía”, op. cit., pp. 274-275.

36 Ídem.

37 Este artículo establecía que los obreros y empleados "serán llamados a colaborar, al lado de los patronos y con igualdad de derechos, en la reglamentación de las condiciones de la retribución 
el borrador sobre el que comenzó a trabajar la Asamblea de 1919, sino que fue incorporado y redactado por obra del jurista socialdemócrata Hugo Sinzheimer ${ }^{38}$. Heller es consciente de la importancia de este artículo para el diseño del texto constitucional y por eso afirma que en él se contiene el pensamiento más original y, tal vez, "el de más halagüeño futuro de la revolución y de la constitución"39.

Al igual que hiciera Sinzheimer al momento de defender esta disposición ante sus pares, Heller distingue estos consejos de aquellos que reivindicaba la extrema izquierda, inspirándose en la experiencia bolchevique. Consciente de los recelos que este tipo de institución despertaba en los críticos de la constitución, destaca que el de consejos es un concepto muy "diversamente" explicado y reclamado tanto por el comunismo como por grupos ultraconservadores. En efecto, estos últimos propiciaban un tipo de representación profesional corporativa y muy poco democrática.

Tal vez por eso es que se ocupa de lo que, entiende, es la idea que inspira la introducción de los consejos a nivel constitucional: la de extender la democracia política a la dimensión económica. Desde su perspectiva, el socialismo es precisamente democracia económica y esta consiste en que los comuneros participen en la dirección y compartan la responsabilidad de la economía. La idea medular de los consejos radica entonces en que éstos sean "órganos de administración autónoma, a través de los cuales participe la población activa en la dirección y responsabilidades de la comunidad" 40 .

Finalmente, en la interpretación que hace Heller de la esencia del artículo 165, se refleja su mirada sobre el Estado social de derecho. La fundación del sistema de consejos implica también un rechazo de la dictadura de derecha como la de izquierda. Se trata de evitar la "versión violenta de la lucha de clases"41, pero al mismo tiempo de asegurar la participación de trabajadores y empleados en la economía en condiciones de igualdad con los empresarios, sin entregar a los consejos todo el poder político y económico, "sino tan sólo de un sector muy reducido, si bien de la mayor importancia" 42 .

y el trabajo, así como en todo el desenvolvimiento económico de las fuerzas productivas". Además proclamaba la existencia y regulaba el funcionamiento de los Consejos obreros de empresa (Betriebsarbeiterräten), los Consejos de obreros de distrito agrupados por regiones económicas, y el Consejo obrero del Imperio (Reichsarbeiterrat) "para defensa de sus intereses sociales y económicos". Los Consejos obreros de distrito y el Consejo obrero del Imperio, unidos con las representaciones de los patronos y demás clases interesadas de la población, formaban Consejos económicos de distrito y un Consejo económico del Imperio (Reichswirtschaftsrat) y eran "llamados a entender en todas las cuestiones de orden económico y a cooperar en la ejecución de las leyes socializadoras".

38 Sobre su rol en el diseño de la democracia económica de la Constitución de Weimar me he ocupado en Leticia Vita, "Constitucionalismo social como democracia económica. Una relectura de la Constitución de Weimar a la luz del aporte de Hugo Sinzheimer", Historia constitucional. Revista Electrónica de Historia Constitucional, n¹9, pp. 565-591, 2018.

39 Hermann Heller, "El derecho constitucional de la República de Weimar. Derechos y deberes fundamentales. Sección V: De la Economía”, op. cit., p. 279.

40 Ídem.

41 Ídem.

42 Ídem. La misma idea la había desarrollado Sinzheimer ante la asamblea y aparece también desarrollada en Hugo Sinzheimer, Das Rätesystem: Zwei Vorträge zur Einführung in den Rätegedanken, Union Druckerei und Verlagsanstalt, Frankfurt am Main, 1919. 
En sintesis, encontramos en este temprano análisis que realiza Heller de la Constitución de 1919 una defensa de lo que interpreta como la principal decisión de la asamblea constituyente de Weimar: la de implementar, mediante la sección $\mathrm{V}$ de la constitución, un programa social, aún no socialista, que represente una alternativa a la dictadura de derecha y al bolchevismo. Sus disposiciones no son directamente operativas sino programáticas, deben guiar la legislación futura, son principios que definen el carácter de la constitución. Como principios estructurales, son además los que deben orientar la interpretación constitucional. Estas ideas, veremos a continuación, serían profundizadas por Heller años más tarde, cuando la República se enfrentara a los mayores desafíos $\mathrm{y}$ ataques.

\subsection{Libertad y forma en la Constitución: una constitución para el futuro}

El segundo texto que nos interesa discutir aquí es un discurso que Heller diera con motivo de la festividad de la constitución celebrada por la asociación alemana de estudiantes en 1930 y que fuera publicado luego con el título "Libertad y forma en la Constitución del Imperio". Como mencionamos, el contexto de este discurso es muy distinto al del artículo de 1924. Muchas disposiciones de la constitución no habían podido ser llevadas a la práctica debido a la crisis política y a la oposición de gran parte del poder judicial. Asimismo, la imposibilidad de formar gobierno en el parlamento y la escalada de violencia politica habian extremado los desafios a la normalidad constitucional.

Por ese motivo Heller elige destacar las potencialidades de la Constitución de Weimar y no los logros conseguidos en una década de vida. La legitimidad del texto de 1919, sostiene, no puede derivarse de "reminiscencias históricas". No debe temer a la pregunta por lo conseguido en esos once años, pero es preciso "dejar la mirada retrospectiva solemne para tiempos más tranquilos y satisfechos"43. Esto se debe a que la constitución "está demasiado próxima a nosotros" y por eso es todavía "objeto de la lucha actual (Gegenstand des aktuellen Kampfes)", a la vez que "demasiado tarea y muy poco cumplimiento (zu sehr Aufgabe und viel zu wenig Erfüllung)". Por eso, cree Heller, es mejor celebrarla "en su significado presente y el futuro" 44.

Esto lo lleva a destacar lo que entiende es la esencia de toda constitución y lo que, como explicará más adelante, hace más valioso el texto de 1919. Para Heller, una constitución es siempre la norma fundamental y, por ende, "la forma política básica de la cooperación de los poderes sociales dentro de un pueblo" 45 . Citando a Hegel, la define como la articulación del poder estatal, pero al mismo tiempo, con referencia explícita a Lassalle, como la expresión de las relaciones fácticas del poder. Por eso la validez de una constitución, entiende, no puede definirse por la hoja de papel o por la norma jurídica ideal. Lo decisivo es "qué relaciones fácticas de poder permite, aprueba o rechaza una constitución y para qué relaciones futuras de poder es útil"46.

\footnotetext{
${ }^{43}$ Herman Heller, "Libertad y forma en la Constitución del Imperio", op. cit., p. 61.

44 Ídem.

45 Ídem.

46 Ibíd., p. 62.
} 
Para Heller la constitución no debe ser algo estático, que condene a las generaciones futuras a atarse a restricciones impuestas por las pasadas. Una constitución es buena siempre que "deje a las fuerzas del pueblo que forjan el porvenir, libertad para la formación politica futura"47. De esa manera, la constitución más perfecta será aquélla en la que la relación necesaria de tensión entre libertad y forma fuese superada "y la forma sociopolítica de todos los miembros se afirmase en libertad"48. Esta relación entre "la forma creada" y la "libertad creadora" es decisiva a la hora de valorar una constitución según Heller.

En este punto cobran especial importancia los ya mencionados principios jurídicos fundamentales o principios éticos del derecho, que son la base de la interpretación constitucional helleriana. Debido a que su contenido es variable de acuerdo a la evolución de cada sociedad, permitirian la continuidad y la vigencia de una constitución en el tiempo ${ }^{49}$. En efecto, Heller ejemplificaría este tipo de disposiciones unos años más tarde en su Teoría del Estado. Allí, tomando como ejemplo cuando el legislador remite a los principios de las buenas costumbres, la buena fe o la equidad, afirma que en realidad esta reconociendo dos cosas: primero, la necesidad de la norma de ser completada por una normalidad social y segundo, "la incapacidad en que se halla para establecer, de una vez para siempre, el contenido, históricamente cambiable en la mayoría de los casos, de las normas sociales que complementan a las jurídicas"50.

Cabe destacar que en la concepción helleriana del Estado y el derecho, el equilibrio entre forma y libertad será más sencillo cuando la pluralidad sea "relativamente homogénea espiritual y socialmente"51. Recordemos que la noción de homogeneidad ${ }^{52}$, se define para Heller en términos de democracia social y es parte de los presupuestos materiales de la democracia. Heller entiende que una democracia de masas con una gran disparidad "económica y espiritual"53 representa un verdadero problema para lograr acuerdos colectivos. Su

47 Ibid., p. 62.

48 Ídem.

49 Carlos Miguel Herrera destaca que en este punto radica la respuesta de Heller al problema del cambio y la continuidad constitucional. Son los principios éticos los que aseguran la permanencia de la norma constitucional, que puede ser armonizada con el cambio ininterrumpido de la realidad social. ver Carlos Miguel Herrera, "Hermann Heller, constitutionnaliste socialiste", en Carlos Miguel Herrera (ed.), Les juristes de gauche sous la république de Weimar, Kimé, Paris, 2002, p. 82.

${ }^{50}$ Hermann Heller, Teoría del Estado, op. cit., p. 276.

51 Herman Heller, "Libertad y forma en la Constitución del Imperio", op. cit., p. 62-63.

52 El concepto de homogeneidad es utilizado también por Schmitt aunque en un sentido completamente distinto. Sobre el tema ver Pasquale Pasquino, "Politische Einheit, Demokratie und Pluralismus. Bemerkungen zu Carl Schmitt, Hermann Heller und Ernst Fraenkel", en Christoph Müller e Ilse Staff (edit.), Staatslehre in der Weimarer Republik: Hermann Heller zu ehren, Baden Baden, Nomos, 1985.

53 Cabe aclarar que Heller entiende por "espiritual” los elementos culturales. Para Heller, la cultura tiene un carácter fuertemente integrador. Así, el sentimiento subjetivo nacional y la conciencia nacional se cimentan en la diversidad y la especificidad ya existentes, porque lo esencial para formar parte de esa comunidad no son tanto los caracteres heredados como los adquiridos en el trabajo conjunto. Ver especialmente Hermann Heller, “Socialismo y Nación”, en Hermann Heller, Escritos politicos, op. cit. 
supervivencia depende, en un grado mucho mayor que cualquier otra forma politica, de la justicia social.

De allí que su diagnóstico de la situación social en 1930 sea pesimista. Su época, interpreta, se encuentra más alejada que cualquiera de las anteriores de este tipo de homogeneidad. Pero eso no se le puede achacar a la constitución de 1919. Fiel a su concepción de la constitución como un reflejo de las fuerzas sociales, entiende que esa comunidad de valores socialmente justa, necesaria para un equilibro social, "no puede crearse con decretos jurídicos"54. Una constitución es buena cuando realiza "la forma históricamente necesaria" convirtiendo "en formas posibilitadoras de cultura la lucha históricamente inevitable", pero al mismo tiempo dejando a las fuerzas creadoras "la libertad para forjar un futuro más bello"55.

Heller defiende, entonces, el texto constitucional de Weimar de quienes le achacaban el proceder de una derrota. Desde su punto de vista es precisamente este hecho el que lo "honra altamente" 56 . Y por eso se pregunta dónde estaban esos críticos cuando fueron puestas las bases de esta constitución, cuando quienes fueron conscientes de la responsabilidad que tenían entre manos "se opusieron al caos" poniendo en riesgo su vida, mientras los verdaderos culpables de esa situación o bien huían al extranjero o bien, "pedían a voces la Asamblea Nacional constituyente y el techo protector de la democracia"57. Estos críticos, entiende, sólo demuestran ingratitud, incomprensión e insolencia cuando afirman que la constitución fue impuesta por la Entente.

Heller concluye que es muy fácil, cuando la república democráticoparlamentaria está implantada, criticar ese diseño bajo la protección de sus garantías constitucionales de libertad. En clara referencia a Schmitt proclama que muy "cultos e ingeniosos" parecen los críticos de izquierda y de derecha que le reprochan a la Constitución de Weimar "la falta de estilo, echan de menos el espíritu unitario y le censuran que no haya tomado las decisiones politicas fundamentales, sino que las haya eludido, las haya aplazado"58.

Desde su punto de vista, no es necesario ser un teórico muy agudo para descubrir las contradicciones en la segunda parte de la Constitución. Estas contradicciones, nuevamente, no obedecen a la hoja de papel, sino a las relaciones de fuerzas vigentes en ese momento. Por eso afirma que si se les preguntase ahora a esos críticos qué decisiones fundamentales consideran ellos correctas y posibles en la situación de poder dada, tendría lugar "un silencio muy embarazoso"59. Muy fácilmente se podría haber decretado una economía puramente socialista o una economia totalmente libre, pero ninguna de esas disposiciones hubiera ido más allá del papel, por no corresponderse con los factores reales de poder.

\footnotetext{
${ }^{54}$ Herman Heller, "Libertad y forma en la Constitución del Imperio", op. cit., p. 63.

55 Ídem.

56 Ídem.

${ }^{57}$ Ibid., pp. 63-64

58 Ídem.

59 Ídem.
} 
El hecho de que estas contradicciones se encuentren en la situación social e histórica dada, implica que es ahí de donde deben ser eliminadas primero. Que el texto de 1919 habilite esa posibilidad es justamente su mejor cualidad. La Constitución de Weimar "ha dejado abiertas a todas las fuerzas sociales vivas las válvulas jurídicas que permiten una supresión sin violencia de las contradicciones sociales" 60 y esto es lo que le da su singularidad.

En ese contexto, la Constitución de Weimar permitiría un modelo alternativo a la dictadura de derecha e izquierda. Como buen intérprete de su época, Heller es consciente de que "los antiguos ideales de forma política ya no sirven y los nuevos todavía carecen de validez" 61 . Se trata de un momento de cambios. La monarquía se ha convertido en un "asunto cinematográfico". El Estado liberal de derecho ya no es capaz de hacer frente a los desafios del presente. Sin embargo, al mismo tiempo la forma política de un Estado social de derecho está sólo en gestación.

Por eso concluye que la forma politica abierta de la Constitución de Weimar era y es la única salida adecuada. Esa es la razón por la que debe ser protegida y debe exigirse para ella respeto, ya que concede la libertad de realizar en el futuro "una forma superior y más homogénea"62. Heller entiende que eso mismo debe exigirse a todo ciudadano, sin importar su orientación política, porque la constitución garantiza a todos los grupos idénticas "condiciones de lucha" 63 . Introduciendo, finalmente, un rol activo para la ciudadanía en la defensa de la constitución, Heller afirma su compromiso de defenderla frente a los ataques de los "ideólogos de la violencia", incluso -como lo había hecho en el pasado- "con las armas en la mano"64.

\subsection{Metas y límites de una reforma constitucional: la constitución del Estado social de derecho}

En último lugar, Heller volvería a ocuparse de la Constitución de Weimar en otro breve texto que fuera publicado por primera vez en el año 1931 y que se titula "Metas y límites de una reforma de la Constitución alemana". Al igual que en su escrito de 1930, Heller da cuenta aquí de la compleja situación y de los ataques que estaba viviendo la república. Y lo hace abordando un tema que se habia convertido en una de las discusiones recurrentes de la academia iuspublicista: el de la reforma constitucional ${ }^{65}$.

Heller reconoce que en muchos círculos, especialmente en aquellos que detentaban poder, predominaba la opinión de que el diseño institucional vigente no era satisfactorio y que los problemas internos y externos del país se

60 Ibid., p. 65.

61 Ídem.

62 Ídem.

63 Ídem.

64 Ídem.

65 Gusy destaca que la discusión sobre la reforma de la constitución de Weimar es tan vieja como la constitución misma. Ver Christoph Gusy, "Selbstmord oder Tod? Die Verfassungsreformdiskussion der Jahre 1930-1932”, Zeitschrift für Politik, Neue Folge, Vol. 40, nº. 4, 1993, pp. 393-417. 
relacionaban con "los defectos presuntos o reales de la Constitución de Weimar"66. Esta conexión entre la crisis de la república y la constitución de 1919 es para él totalmente incorrecta, ya que en ningún caso y menos en el del texto de Weimar se puede responsabilizar al orden jurídico de la situación política de hecho. El problema, entonces, se encuentra en la voluntad politica. Desde su perspectiva, una voluntad de poder con metas claras habria podido lograr "sin cambiar un solo artículo de la Constitución de Weimar, una constitución política y social alemana incomparablemente mejor"67.

Ahora bien, para el caso de que una reforma constitucional fuera inevitable, Heller decide presentar lo que entiende, son los puntos innegociables de tal proceso. Estos principios rectores serian: "la supremacía autoritaria del Estado (die autoritäre Überordnung des Staates) sobre la sociedad, en particular sobre la economía", "el origen democrático de la autoridad política" y los "límites precisos de la autoridad estatal"68. En otras palabras, lo innegociable es el Estado social de derecho. Concepto que no se encontraba en el texto de la Constitución de Weimar pero cuyo articulado sentaría sus principios estructurales.

Heller habla de Estado "autoritario" para denotar una fuerte presencia estatal en la economía. La constitución precisa de un modelo diferente al Estado liberal, ya que éste nunca podría lograr "los grandes cometidos espirituales, morales y económicos" que plantea una economía socialista, porque se ha dedicado a garantizar "la anarquía espiritual y económica de la sociedad capitalista-burguesa"69. Para lograr sus objetivos, el Estado debe conseguir el poder fáctico necesario y dejar de "ser pupilo de los poderes del capitalismo privado" para apropiarse "de un poder económico activo en el interior y el exterior"70.

Recordemos que nuestro autor ya se ha había pronunciado a favor de un "justo señorío"71 del Estado sobre la economía en su obra Socialismo y Nación, de 1925. Proponía la preponderancia de la racionalidad política por sobre la económica, pero sin caer en una economía de Estado, "y mucho menos de la disolución del Estado en la Economía"72. Ese mismo año, en una ponencia que diera en Jena con el título "Estado, Nación y socialdemocracia"73, definiría este orden como el de una "economía comunitaria", que abarcaría la racionalización de la producción a fin de aumentar las mercancías, la socialización para aspirar a una justa distribución y la humanización de las condiciones de trabajo, para lograr una identificación del hombre con su obra.

\footnotetext{
66 Hermann Heller, "Metas y límites de una reforma de la Constitución alemana", op. cit., p. 69.

67 Ídem.

68 Ibid., p. 70.

69 Ídem.

70 Ídem.

71 Hermann Heller, "Socialismo y Nación", op. cit., p. 139.

72 Ibíd., p. 182.

73 Publicada originalmente en Dritte Reichskonferenz der Jungsozialisten, Berlín, 1925 y en español, "Estado, Nación y Socialdemocracia”, en Hermann Heller, Escritos politicos, op. cit., pp. 225-239.
} 
La legitimidad de este modelo de Estado se encuentra en la soberanía popular. Y este es, desde la perspectiva de nuestro autor, el segundo aspecto innegociable de una posible reforma constitucional: el origen democrático del poder político. En este punto su discurso parece dirigirse nuevamente contra Schmitt. Heller afirma aquí su combate contra la dictadura "y la impostura fascista de una 'democracia plebiscitaria" 74 , ya que esto significaría la "completa inhabilitación civil del pueblo" y "la imposibilidad de toda educación política propia"75.

Así, como buen intérprete de la inestabilidad política que sufría la república, Heller propone un fortalecimiento de la autoridad del gobierno a fin de que no fuera un "juguete de las facciones ni un juguete del presidente" 76 . Para lograrlo no cree que sea suficiente la institución del voto de desconfianza, sino que sugiere algún tipo de apelación directa al pueblo, para que éste pueda apoyarse en él "más allá de los partidos"77. En definitiva, para Heller el principal problema de una revisión de la constitución era la lograr que el parlamento fuera capaz de trabajar y el gobierno de actuar.

Así llega al que identifica como el tercer y último elemento del que no se debería prescindir en una reforma constitucional: el de la legalidad del estado de derecho. La Constitución de Weimar proponía una preponderancia del Estado sobre el ámbito privado económico liberal, pero siempre respetando las herramientas del estado de derecho. Por eso proclama Heller que "deseamos el Estado autoritario, pero luchamos contra el Estado total (Wir wünschen den autoritären Staat, wir bekämpfen aber den totalen Staat)"78. El Estado total, que puede leerse en clave schmittiana, es definido por Heller como aquel "cuya autoridad no conoce los límites del derecho ni la división de poderes ni los derechos fundamentales"79. Asi para Heller se trata de someter "el orden del trabajo y de los bienes a la organización del Estado material de derecho", transformando el Estado liberal en un Estado socialista de derecho, pero sin eliminar el estado de derecho.

\section{CONCLUSIONES}

Hemos visto que la interpretación que hace Heller de la Constitución de Weimar apunta en contra de las miradas más críticas a las que se enfrentó el texto sancionado en 1919. Su exégesis de los derechos incorporados en la segunda parte, le permite definirla como una constitución con decisión. Una opción por un modelo conciliatorio que tiene como objetivo la extensión de la

${ }^{74}$ Hermann Heller, "Metas y límites de una reforma de la Constitución alemana", op. cit., p. 72.

75 Ídem.

76 Ibid., p. 73.

77 Ídem. Aunque deja abierta la forma en que se articularía esta apelación.

78 Ibid., p. 73.

79 Ídem. Se trata de un término que Schmitt utiliza en distintas oportunidades en su Legalidad y Legitimidad (Legalität und Legitimität), El giro hacia el Estado total (Die Wendung zum totalen Staat) y Perfeccionamiento del Estado total en Alemania (Weiterentwicklung des totales Staates in Deutschland). Sobre el tema ver Jean François Kervégan, Hegel, Carl Schmitt. Lo politico: entre especulación y positividad, Madrid, Escolar y Mayo, 2007. 
democracia política al ámbito económico y que refleja, ni más ni menos, las relaciones de fuerzas existentes en la sociedad alemana de 1918-19.

Heller le responde también a quienes veían a la Constitución de Weimar como un texto impuesto por la derrota bélica. La describe como una constitución dinámica, que incorpora principios reguladores que permiten la continuidad y el cambio a partir de la interpretación jurídica. Aún en los momentos más difíciles de la república, Heller hace su mejor lectura de los preceptos incorporados en 1919, defendiendo la potencialidad de sus disposiciones y no deteniéndose en los aspectos aún no logrados o desarrollados.

Finalmente, se enfrenta también a aquellas visiones que encuentran en la Constitución de Weimar la causa de todos los males de la república. El problema es político, no jurídico, ya que desde su perspectiva el texto de 1919 permite, sin cambiar ni un solo artículo, tomar las medidas necesarias para implementar un modelo de Estado social y de derecho. En otras palabras, Heller apunta al que fue el principal problema de la primera experiencia democrática alemana: la falta de un acuerdo politico capaz de hacer efectivo el programa constitucional.

En sintesis, ¿qué nos dice este balance sobre su teoría de la interpretación constitucional? Fundamentalmente confirma la importancia que le da Heller a los principios éticos del derecho para la interpretación de la constitución. Las disposiciones de la sección $\mathrm{V}$ son entendidas por nuestro autor como aquellas que encierran los principios sociales estructurales de la constitución. No son meros ideales sin valor alguno sino que deben entenderse como verdaderas guías para que el poder legislativo actúe y eventualmente el judicial aplique.

En la coyuntura histórica de Weimar la apuesta de Heller, podemos suponer, no es al poder judicial conservador y reacio a esas políticas sociales, sino al legislativo. Sin embargo, nada impide que podamos reconstruir esta teoría a la luz de otros tiempos y otros desafios. La interpretación que hace Heller del texto de Weimar nos invita a repensar las estrategias y alcances de cualquier teoria de la interpretación que tenga como objeto una constitución con contenido social.

Enviado el (Submission Date): 26/04/2019

Aceptado el (Acceptance Date): 8/05/2019 